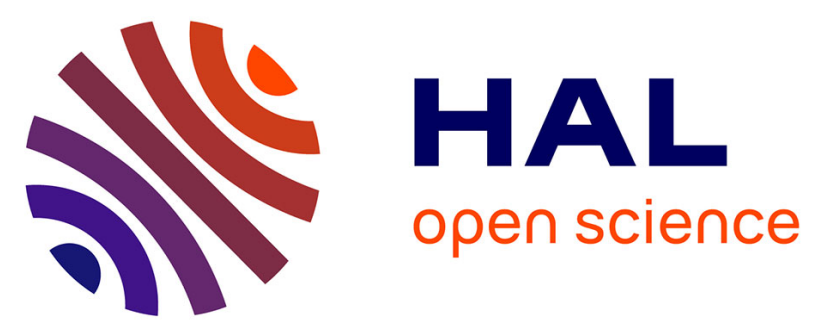

\title{
Nitrogen-Doped Graphitized Carbon Electrodes for Biorefractory Pollutant Removal
}

Thi Xuan Huong Le, Roseline Esmilaire, Martin Drobek, Mikhael Bechelany, Cyril Vallicari, Sophie Cerneaux, Anne Julbe, Marc Cretin

\section{- To cite this version:}

Thi Xuan Huong Le, Roseline Esmilaire, Martin Drobek, Mikhael Bechelany, Cyril Vallicari, et al.. Nitrogen-Doped Graphitized Carbon Electrodes for Biorefractory Pollutant Removal. Journal of Physical Chemistry C, 2017, 121 (28), pp.15188 - 15197. 10.1021/acs.jpcc.7b03100 . hal-01674779

\section{HAL Id: hal-01674779 \\ https://hal.umontpellier.fr/hal-01674779}

Submitted on 10 Jun 2021

HAL is a multi-disciplinary open access archive for the deposit and dissemination of scientific research documents, whether they are published or not. The documents may come from teaching and research institutions in France or abroad, or from public or private research centers.
L'archive ouverte pluridisciplinaire HAL, est destinée au dépôt et à la diffusion de documents scientifiques de niveau recherche, publiés ou non, émanant des établissements d'enseignement et de recherche français ou étrangers, des laboratoires publics ou privés. 


\section{Nitrogen-doped Graphitized Carbon Electrodes for Biorefractory}

\section{Pollutants Removal}

Thi Xuan Huong Le ${ }^{\mathrm{a}, \mathrm{b}}$, Roseline Esmilaire ${ }^{\mathrm{a}}$, Martin Drobek ${ }^{\mathrm{a}}$, Mikhael Bechelany ${ }^{\mathrm{a}}$, Cyril Vallicari $^{\mathrm{a}}$, Sophie Cerneaux ${ }^{\mathrm{a}}$, Anne Julbe ${ }^{\mathrm{a}}$, Marc Cretin ${ }^{\mathrm{a}}$

anstitut Européen des membranes, IEM UMR-5635, Université de Montpellier, ENSCM, CNRS, Place Eugène Bataillon, 34095 Montpellier cedex 5, France.

bVan Lang University, 45 Nguyen Khac Nhu, District 1, Ho Chi Minh City, Viet Nam.

* Corresponding authors: $\quad$ mikhael.bechelany@umontpellier.fr $\quad$ and Marc.Cretin@umontpellier.fr

\section{ABSTRACT}

A novel material was fabricated by deposition of graphitized Nitrogen-doped Porous Carbon layer (NPC) on commercial Carbon Felt (CF). The NPC was obtained via Atomic Layer Deposition of zinc oxide $(\mathrm{ZnO})$ and its subsequent solvothermal conversion to Zeolitic Imidazolate Framework (ZIF-8) followed by its carbonization under controlled atmosphere. Both physical and electrochemical properties have been evaluated by Scanning Electron Microscopy, X-Ray Diffraction, Energy-Dispersive X-ray spectroscopy, X-ray photoelectron spectroscopy, Raman spectroscopy, nitrogen sorption, contact angle and cyclic voltammetry measurements. The parameters affecting the growth of NPC, such as the amount of $\mathrm{ZnO} / \mathrm{ZIF}-8$ material before calcination and thermal treatment temperature have been investigated in details. The versatility of the as-prepared NPC/CF material was assessed by studying: $i$ ) its adsorption ability and/or $i$ ) its behavior as cathode in Electro-Fenton process (EF) for the elimination of a model refractory pollutant (acid orange 7 (AO7)). Once used as adsorbent, the NPC/CF proved good adsorption 
capacity with $97 \%$ color removal of initial $0.02 \mathrm{mM}$ dye concentration after $30 \mathrm{~min}$. Moreover, the application of such novel cathode could also reduce the cost for EF technology by using lower energy consumption at $0.54 \mathrm{kWh} \mathrm{g}^{-1}$ TOC. The apparent rate constant $\left(\mathrm{k}_{\mathrm{app}} \sim 0.8 \mathrm{~min}^{-1}\right)$ obtained for NPC/CF was more than 7 times higher compared to pristine $\mathrm{CF}$ commercial electrode, thus leading to more than $90 \%$ TOC removal in $8 \mathrm{~h}$. In addition, high reaction efficiency and system durability were attributed to continuous regeneration of the NPC/CF sorption capacity upon total mineralization of the pollutants accumulated at the electrode surface. Results confirmed that the new NPC/CF material behaves as a highly active electrode with attractive adsorption efficiency and at the same time it possess an excellent electrochemical activity in Electro-Fenton (EF) oxidation process for the removal of persistent water pollutants. 


\section{INTRODUCTION}

Among different Electrochemical Advanced Oxidation Processes (EAOP), ElectroFenton (EF) system is considered as a highly efficient technology in wastewater treatment, namely for the degradation of refractory pollutants. In fact, EF process allows the elimination of Persistent Organic Pollutants (POPs) via the production and reaction of powerful oxidant hydroxyl radicals $(\bullet \mathrm{OH})$ inducing their total mineralization. The $\bullet \mathrm{OH}$ radicals are produced in electrochemically assisted Fenton's reaction involving hydrogen peroxide $\left(\mathrm{H}_{2} \mathrm{O}_{2}\right)$ and ferrous iron as indicated in Eq. $1^{1}$.

$$
\mathrm{Fe}^{2+}+\mathrm{H}_{2} \mathrm{O}_{2} \rightarrow \mathrm{Fe}^{3+}+\mathrm{OH}^{-}+{ }^{\cdot} \mathrm{OH}
$$

Since this reaction takes place in acidic medium, it can be alternatively expressed as follows (Eq. 2):

$$
\mathrm{Fe}^{2+}+\mathrm{H}^{+}+\mathrm{H}_{2} \mathrm{O}_{2} \rightarrow \mathrm{Fe}^{3+}+\mathrm{H}_{2} \mathrm{O}+{ }^{\circ} \mathrm{OH}
$$

$\mathrm{H}_{2} \mathrm{O}_{2}$ is formed via two-electrons oxygen reduction reaction (ORR) (Eq. 3) at the cathode and the efficiency of its production is thus a key parameter of EF process.

$$
\mathrm{O}_{2}+2 \mathrm{H}^{+}+2 \mathrm{e}^{-} \rightarrow \mathrm{H}_{2} \mathrm{O}_{2}
$$

Hence, the improvement of cathode material in ORR, increasing $\mathrm{H}_{2} \mathrm{O}_{2}$ production, is of high importance for enhancing the EF process efficiency. Carbon-based electrodes are commonly used as cathodes in oxygen-dissolved solutions to produce $\mathrm{H}_{2} \mathrm{O}_{2}$. In a form of commercial carbon felts (CF), they possess numerous advantages including good conductivity, high chemical and thermal stability, decent mechanical integrity and, last but not least, easy hanging and commercial availability at low cost ${ }^{2-3}$. In addition, the $\mathrm{CF}$ enables an efficient regeneration of $\mathrm{Fe}^{2+}\left(\mathrm{Fe}^{3+}+\mathrm{e}^{-} \rightarrow \mathrm{Fe}^{2+}\right)$, thus making it a very attractive cathode material in EF process ${ }^{4-6}$. In order to upgrade the performance of commercial CF in ORR, various strategies have been proposed including cathode modification by thermal treatment ${ }^{7}$ or deposition of carbon-based additives such as graphene ${ }^{8-9}$. 
Recently, porous carbon (pC) derived from Metal-Organic Frameworks (MOFs) has emerged as an effective material for a variety of applications including capacitive deionization ${ }^{10}, \mathrm{CO}_{2}$ adsorption ${ }^{11}$, fuel-cells ${ }^{12}$, and electrochemical applications ${ }^{13}$. Several pCs have been reported originating from different MOF types, including MOF-5 $\left(\mathrm{Zn}_{4} \mathrm{O}\left(\mathrm{OOCC}_{6} \mathrm{H}_{4} \mathrm{COO}\right)_{3}\right)^{14}$, zeolitic imidazolate framework (ZIF-8) ${ }^{10,13}$, isoreticular metal-organic framework-3 (IRMOF-3) 15, MOF-199 ${ }^{16}$, etc. The pC material is typically obtained by thermal treatment under inert atmosphere forming an ordered and calibrated porous structure with high specific surface area and large pore volume. It has been demonstrated that the doping of $\mathrm{pC}$ by nitrogen atoms (i.e. pyridinic-N, pyrrolic-N, and quaternary-N) improved significantly the catalytic activity towards ORR ${ }^{17-19}$ by decreasing the adsorption energy of oxygen at the electrode surface ${ }^{20-22}$ and enhancing the electro-conductivity. Systems with high activity can thus be derived by coupling the N-doping effect with high electroactive surface area ${ }^{15}$. Furthermore, because of their highly porous structure and high specific surface area, carbon materials are also known as adsorbents of high interest for wastewater treatment. For instance, Jiao et al. claimed that Co-doped hierarchical porous carbon (Co/HPC) derived from Co/ZIF-8 carbonization is an efficient adsorbent for the extraction of trizine herbicides from wastewater ${ }^{23}$. Nanoporous carbon material obtained by direct carbonization of ZIF-8 was also used as adsorbent for the removal of heavy metal ions from aqueous media ${ }^{24}$.

A large number of approaches have been reported in the literature to produce $\mathrm{pC}$ materials from MOFs: $i$ ) thermolysis combined with HF treatment in aqueous solution ${ }^{24-25}$; ii) microwave-assisted $\mathrm{KOH}$ activation ${ }^{26}$; iii) carbonization in presence of alcohols ${ }^{27}$; iv) direct carbonization/pyrolysis under inert atmosphere ${ }^{16,28-29}$. However, most of these studies just focussed on a direct application of the as-formed porous carbon powders, while the deposition/growth of $\mathrm{pC}$ on different substrates is scarce. For electrochemical applications, electrodes have been modified in slurries containing C/carbon black and polytetrafluoroethylene (PTFE) $25-26,28$. The usage of PTFE as a binder may however lead to some disadvantages like 
weak adhesion onto the electrode surface, low conductivity of the composite, and limited pC loading ${ }^{30}$.

For the sake of overcoming such bottlenecks, in this study, we investigated a novel electrode material fabricated by deposition of graphitized nitrogen-doped porous carbon layer (NPC) on commercial carbon felt (CF). The novelty of the present study bears on the possibility to grow homogeneously the $\mathrm{pC}$ precursor on a large variety of substrates with different size, shape, porosity and morphology. The synthesis strategy is based on atomic layer deposition (ALD) of a metal oxide (e.g. $\mathrm{ZnO}$ ) and its solvothermal conversion to the corresponding MOFs (e.g. ZIF-8), followed by a thermal treatment under inert atmosphere for the formation of pC. It must be noted that the NPC/CF material has a hierarchical structure composed of both macropores providing access of the polluted solution inside the $\mathrm{CF}$ structures, and micropores increasing the specific surface area of the electrode. In addition, the N-doping of pC ensures an increase of electro-conductivity. This, coupled with high electroactive surface area should minimize the energy cost of the developed NPC/CF system.

The as-prepared NPC/CF electrode was employed as multifunctional material acting as both adsorbent and active cathode in EF process for the destruction of $\mathrm{AO} 7$ as a model refractory water pollutant. It is of particular interest that coupling both adsorption and EF oxidation could maximize the process efficiency as EF helps to continuously regenerate the NPC/CF sorption capacity by total mineralization of the pollutants accumulated on electrode surface. We believe that such a versatile approach, enabling possible synthesis of various $\mathrm{pC}$ on numerous electrode substrates and their subsequent applications in electro-Fenton process, is an attractive way for developing a competitive EF process for the destruction of bio-refractory pollutants from waste waters.

\section{EXPERIMENTAL SECTION}

\section{Materials}


Diethyl zinc (DEZ), $\mathrm{Zn}\left(\mathrm{CH}_{2} \mathrm{CH}_{3}\right)_{2}$, (95\%), AO7 (Orange II sodium salt), sodium sulphate (anhydrous, $99.0-100.5 \%$ ), iron (II) sulphate hepta-hydrate (99\%), and methanol (10 wt\%) were obtained from Sigma-Aldrich. The carbon felt was provided by Johnson Matthey Co., Germany. 2-methylimidazole (97\%), potassium hexacyanoferrate $(\geq 99 \%)$ and potassium nitrate ( $\geq 99 \%$ ) were bought from Fluka. TOC standard of $1000 \mathrm{mg} / \mathrm{L}$ (Sigma-Aldrich) and sodium hydrogen carbonate $(\geq 99.5 \%$, ACS, Karlsruhe) were used for calibration. Potassium titanium (IV) oxalate (99.99\%, Alfa Aesar), potassium permanganate (> $99 \%$ ), sulfuric acid (95 - 97\%), and standard hydrogen peroxide solution ( $\geq 30 \% \mathrm{w} / \mathrm{w}$, Sigma-Aldrich) were employed to determine the hydrogen peroxide accumulation in time. The aqueous solutions were prepared using 18.2 M $\Omega \mathrm{cm}$ Milli-Q water (Millipore).

\section{Modification of carbon felt by graphitized nitrogen-doped porous carbon}

The commercial carbon felt (CF) was first cleaned in an ultrasonic bath with acetone for $2 \mathrm{~h}$ to remove any adsorbed contaminants, then rinsed with deionized water and dried at $60^{\circ} \mathrm{C}$ for 24h. Such pretreated carbon felt was denoted as "raw CF". The graphitized nitrogen-doped porous carbon (NPC) layers deposited on raw CF have been prepared by a synthesis protocol described in our previous work ${ }^{31}$. It consists of an original strategy coupling $i$ ) atomic layer deposition (ALD) of a metal oxide (MO) and ii) solvothermal conversion of MO into the corresponding metal organic framework (MOF) followed by its carbonization into porous carbon forming NCP/CF electrodes. The ALD step has been performed using a home-made ALD set-up described elsewhere ${ }^{32}$. The $\mathrm{CF}$ was sequentially exposed to diethyl zinc (DEZ), $\mathrm{Zn}\left(\mathrm{CH}_{2} \mathrm{CH}_{3}\right)_{2}$, and deionized water, separated by a purge step with dry argon (Ar flow rate of $100 \mathrm{sccm}$ ) at $100^{\circ} \mathrm{C}$, thus forming a $\mathrm{ZnO}$ thin layer onto the $\mathrm{CF}$ surface. The characteristics of the $\mathrm{ZnO}$ deposits (thickness, crystalline phase, grain/crystallite sizes) were found as insensitive to support morphology. ZnO films with different thicknesses (20, 50, 75 and $100 \mathrm{~nm}$ ) have been deposited in order to optimise the conversion to ZIF-8 and subsequently the electrochemical performance 
of the NCP/CF electrodes obtained after the carbonisation step. The growth of $\mathrm{ZnO}$ per cycle has been controlled by measuring the thickness of films deposited on Si-wafer companion substrates placed in the ALD reaction chamber. Solvothermal conversion of $\mathrm{ZnO}$ into the corresponding MOF (ZIF-8) has been performed at $100^{\circ} \mathrm{C}$ for $5 \mathrm{~h}$ in a closed pressured vessel (Teflon-lined stainless-steel autoclave - $45 \mathrm{~mL}$ ) containing a solution of 2-methylimidazole (2-mim) in methanol (10 wt\%). The thermal treatment (carbonization) of ZIF-8 has been conducted at $1000^{\circ} \mathrm{C}$ for $10 \mathrm{~h}$ under inert $\mathrm{N}_{2}$ atmosphere, in order to obtain the nitrogen-doped porous carbon (NPC) layer deposited onto the commercial carbon felt (CF), thus forming NPC/CF cathode.

\section{Characterization}

The surface elemental composition of the as-prepared electrodes was determined by Xray Photoelectron Spectroscopy (XPS) on an ESCALAB 250 (Thermo Electron) with Al Ka (1486.6 eV) source. Analyzed surface was $400 \mu \mathrm{m}$ in diameter and the background signal was removed using the Shirley method ${ }^{33}$. The surface atomic concentrations were determined from photoelectron peaks areas using the atomic sensitivity factors reported by Scofield ${ }^{34}$. Binding energies $(\mathrm{BE})$ of all core levels were referred to $\mathrm{C}=\mathrm{C}$ of $\mathrm{C} 1 \mathrm{~s}$ carbon at $284.4 \mathrm{eV}$. The $\mathrm{N}_{2}$ adsorption-desorption isotherms were measured using Micromeritics ASAP2010 equipment (out gassing conditions: $200^{\circ} \mathrm{C}-12 \mathrm{~h}$ in vacuum). Further morphological, chemical and structural characterizations have been performed by scanning electron microscopy (SEM, Hitachi S-4800),

a homemade contact angle meter, X-ray diffraction (XRD) (PANAlytical Xpert-PRO diffractometer equipped with a X'celerator detector using $\mathrm{Ni}$-filtered $\mathrm{Cu}$-radiation) and EDX analysis (Silicon Drift Detector (SDD), X-MaxN, Oxford Instrument) coupled to a Zeiss EVO HD15 SEM analyzer. Electrochemical measurements were carried out in a three-electrode cell using a $\mu 3$ AUT70466 Autolab system (Eco Chemie BV, Netherlands) at room temperature. Cyclic voltammetry $(\mathrm{CV})$ was conducted in a $10 \mathrm{mM} \mathrm{K}_{3}\left[\mathrm{Fe}(\mathrm{CN})_{6}\right]$ and $1.0 \mathrm{M} \mathrm{KNO}_{3}$ solution 
with a working electrode (carbon cathode), a counter electrode (Pt foil), and a reference electrode (Saturated Calomel Electrode, SCE).

\section{Removal of AO7 by adsorption}

Adsorption experiments were performed in a batch experimental set-up containing AO7 solutions with concentrations in the range of $0.02 \mathrm{mM}-0.5 \mathrm{mM}$. The $\mathrm{pH}$ of the solutions was adjusted to $\sim 6.8$ under magnetic stirring $(500 \mathrm{rpm})$ at room temperature. The decolorization of AO7 pollutant was monitored by measuring the dye absorbance at the selected single wavelength of $485 \mathrm{~nm}$ specific to the azo bonds ${ }^{35}$ using Spectrophotometer Jenway 6300 (Barioworld Scientific Ltd, Dunmow UK). All experiments were repeated three times, and average values were used for further calculations.

The NPC/CF surface charge was determined with the help of $\mathrm{Na}_{2} \mathrm{SO}_{4}(50 \mathrm{mM})$ solution ( $\mathrm{pH}=3.0$ to 12.5$)$ adjusted by addition of either sulphuric acid $\left(\mathrm{H}_{2} \mathrm{SO}_{4}\right)$ or sodium hydroxide $(\mathrm{NaOH})$ solutions. The NPC/CF was immersed in a stirred solution continuously bubbled with $\mathrm{N}_{2}$ during experiments in order to avoid any effect of atmospheric $\mathrm{CO}_{2}$ on the $\mathrm{pH}$ of the solutions. At the end of each experiment, the $\mathrm{pH}$ was measured in order to monitor the difference between the initial and final $\mathrm{pH}$ values.

\section{Mineralization of AO7 by electro-Fenton oxidation}

The EF experiments were carried out after the adsorption step (equilibrium reached after 2h). $\mathrm{Na}_{2} \mathrm{SO}_{4}(50 \mathrm{mM})$ as supporting electrolyte and $\mathrm{FeSO}_{4} .7 \mathrm{H}_{2} \mathrm{O}(0.2 \mathrm{mM})$ as catalyst were added to AO7 solution whose $\mathrm{pH}$ was adjusted at $\sim 3$ with $\mathrm{H}_{2} \mathrm{SO}_{4}$ solution $(1 \mathrm{M}){ }^{4}$. At selected time intervals, aliquots of $1 \mathrm{~mL}$ were withdrawn and filtered (at $0.2 \mu \mathrm{m}$ ) before measuring the TOC removal with the help of a TOC-L CSH/CSN Shimadzu (Japan). Calibration curves for total carbon (TC) and inorganic carbon (IC) analyses were obtained by automatic dilution of standards solutions of TOC (potassium hydrogenophtalate) and IC (sodium hydrogen carbonate). 
The specific energy consumption per unit TOC mass $\left(\mathrm{EC}_{\mathrm{TOC}}\right)$ was calculated according to Eq. (4) 36 :

$$
\mathrm{EC}_{\mathrm{TOC}}\left(\mathrm{kWh} \mathrm{g}^{-1} \mathrm{TOC}\right)=\frac{V I t}{\Delta(T O C)_{\exp } V_{s}}
$$

where $\mathrm{V}$ is the average cell voltage $(\mathrm{V}), \mathrm{V}_{\mathrm{s}}$ the solution volume $(\mathrm{L}), \Delta(\mathrm{TOC})_{\exp }$ is the experimental TOC decay $\left(\mathrm{mg} \mathrm{L}^{-1}\right)$, I the applied current (A) and the electrolysis time (h).

\section{RESULTS AND DISCUSSION}

\section{Synthesis and characterization of NPC/CF}

As specified in the experimental part, the graphitized nitrogen-doped porous carbon material deposited on commercial carbon felts (NPC/CF) was fabricated by combining $i$ ) Atomic Layer Deposition (ALD) of metal oxide $(\mathrm{ZnO})$ and $i$ ) solvothermal conversion of $\mathrm{ZnO}$ to $\mathrm{ZIF}-8$, followed by its subsequent carbonisation under controlled atmosphere. The number of ALD cycles has been adjusted in order to control the $\mathrm{ZnO}$ layer thickness as reported elsewhere ${ }^{37}$. After the solvothermal conversion of ALD modified carbon felts, a ZIF-8-based composite material has been obtained on the CF surface (Figure 1a). The SEM images of the CF@ZIF$8 / \mathrm{ZnO}$ composites are shown in Figures $1 \mathrm{~b}$ and $1 \mathrm{c}$, revealing homogeneous coverage of the carbon fibers with ZIF-8 crystals having typical rhombic dodecahedron shape ${ }^{13,}{ }^{38}$. When carbonized in controlled atmosphere, this composite material transforms into nitrogen-doped porous carbon (NPC) thin layer on the CF surface (Figures 1d and 1e). In a good agreement with the literature ${ }^{17}$, the NPC preserved the original polyhedral shape of ZIF-8 (Figure 1f). The EDX mapping (Figures $1 \mathrm{~g}$ to $1 \mathrm{j}$ ) clearly evidenced the presence of $\mathrm{C}, \mathrm{N}$ and $\mathrm{O}$ atoms $(\mathrm{C} 88.9$ at $\%, \mathrm{~N}$ $7.3 a t \%, O 3.6 a t \%)$, proving the formation of nitrogen-doped carbon. 

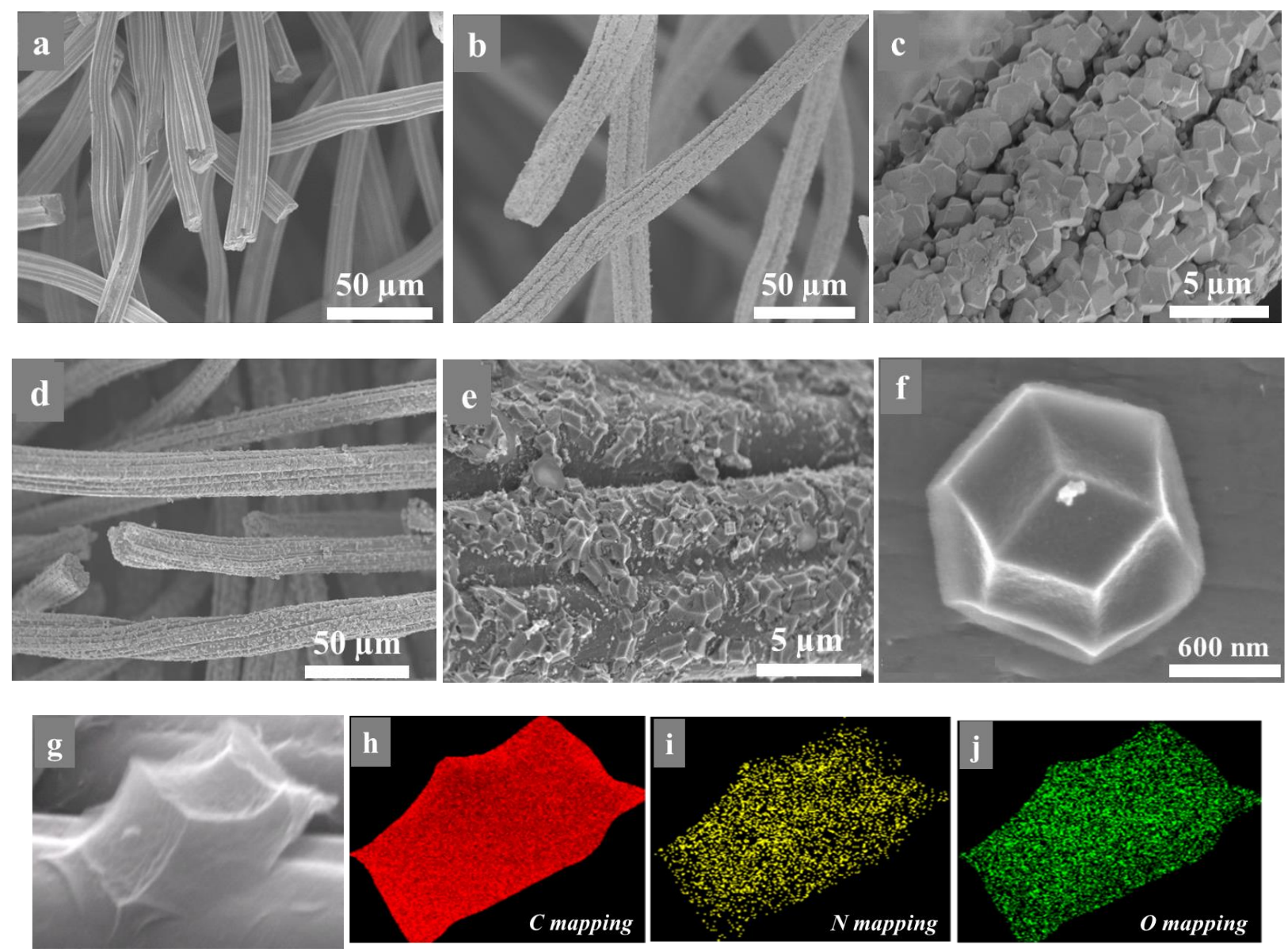

Figure 1. SEM images of (a) raw CF; (b, c) CF@ZIF-8/ZnO composite; (d, e) NPC/CF; (f, g) single porous nitrogen-doped carbon particle; and (h, i, j) EDX mapping of NPC/CF.

Nitrogen-doping of the porous carbon thin layer deposited on CF was proven by the deconvolution of high-resolution XPS spectrum in N1s region (Figure 2). The appearance of nitrogen in NPC/CF could be attributed to N-containing functional groups such as pyridinic-N (398.2 eV), pyrrolic-N (399.8 eV), quaternary-N (400.8 eV) and N-oxide $(403 \mathrm{eV})^{11,13}$. These nitrogen-containing groups are expected to enhance surface hydrophilicity and thus to promote mass transfer between the NPC/CF and the electrolyte. Such characteristic, coupled to the enhanced electron transport and high surface area, should improve the electrochemical performance of the system in ORR during EF process ${ }^{17,39}$. 


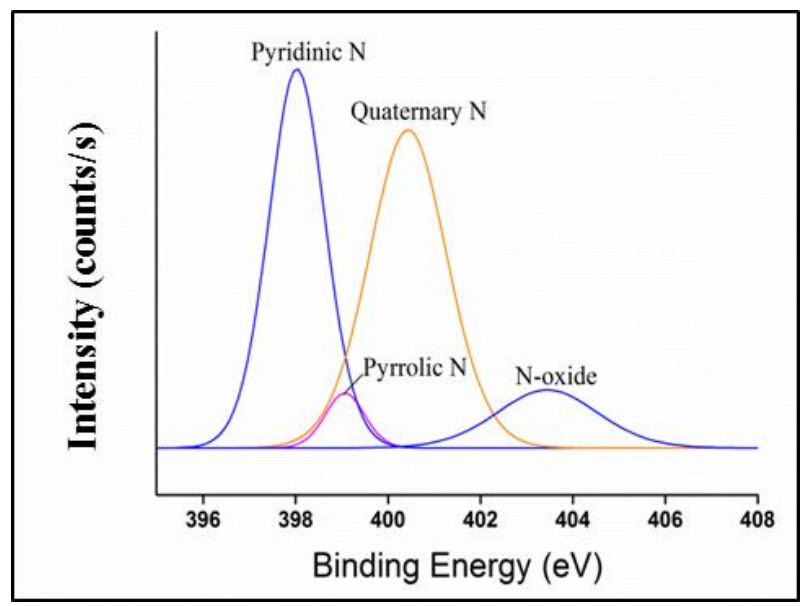

Figure 2. N1s spectrum of NPC/CF (from XPS analysis).

\section{Influence of the synthesis parameters on NPC/CF characteristics}

\subsection{Thickness of $\mathrm{ZnO}$ layer}

The initial thickness of $\mathrm{ZnO}$ layers has been modulated in the range 20-100 $\mathrm{nm}$ by controlling the number of ALD cycles, while other reaction parameters including solvothermal conversion and carbonization steps were kept constant. The electrochemical performance of the $\mathrm{NPC} / \mathrm{CF}$ as a function of initial $\mathrm{ZnO}$ thickness has been evaluated by running cyclic voltammetry (CV) measurements in a $10 \mathrm{mM} \mathrm{K}_{3}\left[\mathrm{Fe}(\mathrm{CN})_{6}\right]$ and a $1.0 \mathrm{M} \mathrm{KNO}_{3}$ solution. The current response of the modified electrode towards $\left[\mathrm{Fe}(\mathrm{CN})_{6}\right]^{3-/ 4-}$ increased with increasing $\mathrm{ZnO}$ thickness (Figure 3d). This phenomenon was attributed to the higher quantity of ZIF-8 obtained by solvothermal conversion of $\mathrm{ZnO}$-richer samples, leading to crystal oriented growth and non-compact stacking ${ }^{38}$, thus yielding higher quantity of NPC after carbonisation. According to $\mathrm{N}_{2}$ physisorption measurements, the specific surface area increased by more than 64 times for NPC/CF sample with $\mathrm{ZnO}$ thickness at $100 \mathrm{~nm}$ in comparison with raw $\mathrm{CF}$ carbon felts $\left(0.09 \mathrm{~m}^{2} \mathrm{~g}^{-1}\right)$. The increase of $\mathrm{ZnO}$ thickness induces the increase of the specific surface area $\left(\mathrm{S}_{\mathrm{BET}}\right)$ (Table $\left.\mathrm{S} 1\right)$ of the final NPC/CF electrode resulting from a higher amount of ZIF-8 formed after the solvothermal conversion step. In fact, the amount of NPC and thus the active surface is raised gradually as a function of the initial $\mathrm{ZnO}$ thickness. The NCP-covered carbon felts obtained after the conversion and carbonisation of samples with different initial amounts of $\mathrm{ZnO}$ are shown in 
Figures $3 \mathrm{a}, \mathrm{b}$ and $\mathrm{c}$. Comparing the activity of pristine and NPC/CF electrodes in $\mathrm{CV}$ measurements evidenced a significant increase of the current density in the case of NCPmodified electrodes, thus proving their promising potential for electrochemical applications.
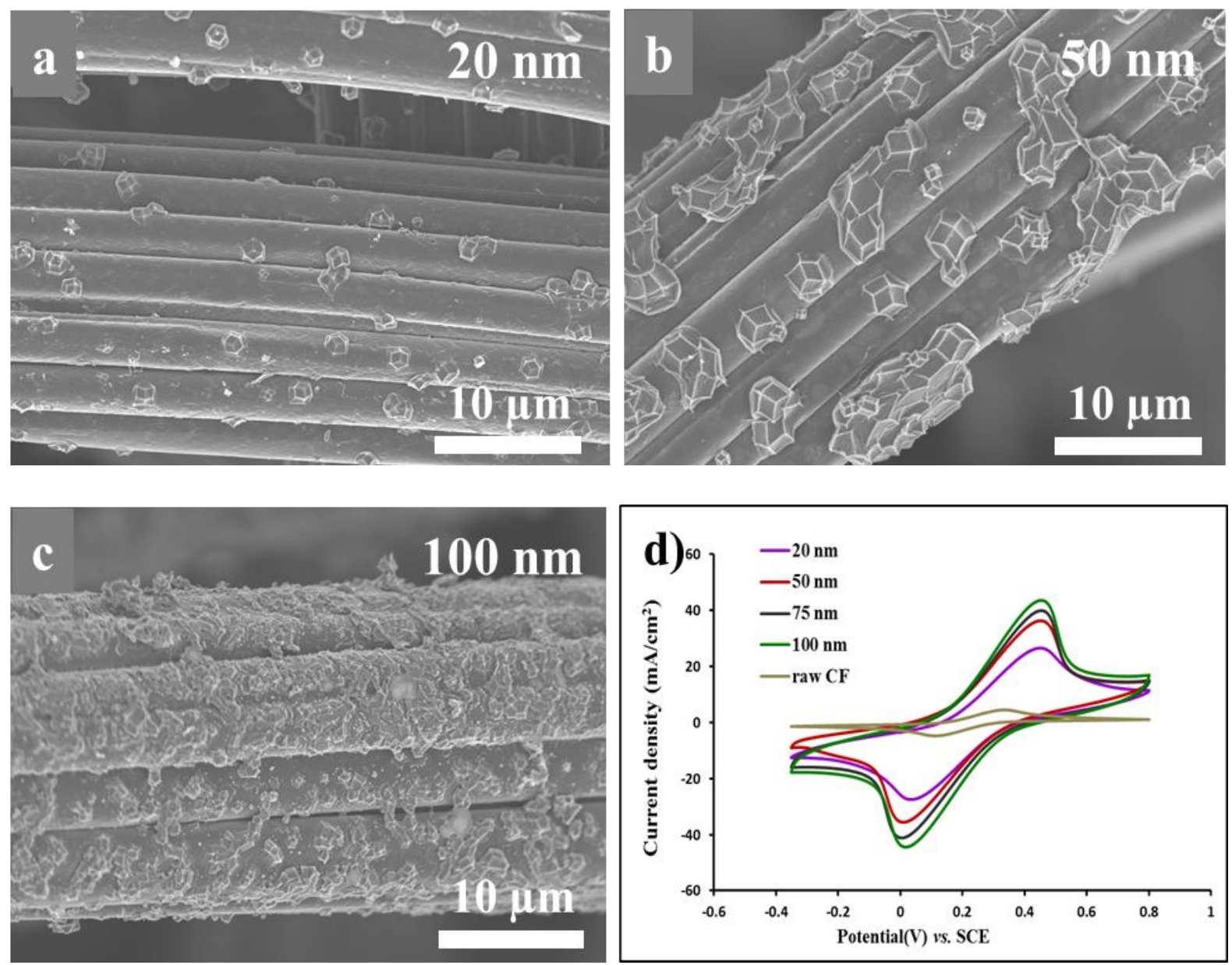

Figure 3. SEM images of NPC/CFs obtained from samples with different initial ZnO thicknesses: (a) $20 \mathrm{~nm}$, (b) $50 \mathrm{~nm}$, (c) $100 \mathrm{~nm}$; (d) CV curve of raw CF and NPC/CF materials obtained from samples with 20,50, 75, $100 \mathrm{~nm}$ initial $\mathrm{ZnO}$ thickness. CV conditions: potassium hexacyanoferrate solution $(10 \mathrm{mM})$ in $1 \mathrm{M} \mathrm{KNO}_{3}$. Scan rate of $7 \mathrm{mV} \cdot \mathrm{s}^{-1}$.

\subsection{Carbonisation treatment}

In order to investigate the effect of carbonisation treatment conditions, series of NPC/CF samples with $100 \mathrm{~nm}$ initial $\mathrm{ZnO}$ thickness (i.e. exhibiting the highest current density in $\mathrm{CV}$ measurements) were prepared by pyrolysing the ZIF-8 at different temperatures and times. Thermogravimetric analysis of the CF@ZIF-8/ZnO composites (Figure 4b) revealed that 
carbonization starts at $600{ }^{\circ} \mathrm{C}$. Sample series were thus prepared by applying $10 \mathrm{~h}$ pyrolysis treatment in the temperature range $600-1200^{\circ} \mathrm{C}$. The $\mathrm{CV}$ curves (Figure $4 \mathrm{a}$ ) reveal that the current density increases with the pyrolysis temperature up to $1000^{\circ} \mathrm{C}$. Above this temperature, virtually-zero improvement of electrochemical performance was detected. This phenomenon could be attributed to the progressive extraction of metallic Zn from the ZIF-8 structure during the carbonization process and its subsequent complete vaporization at $\sim 1000^{\circ} \mathrm{C}$ (the boiling point of $\mathrm{Zn}$ being $\left.\sim 908^{\circ} \mathrm{C}\right){ }^{17}$.

The effect of the calcination time at $1000^{\circ} \mathrm{C}$ has been evaluated in the range from $30 \mathrm{~min}$ up to $24 \mathrm{~h}$. The CV curves (Figure $4 \mathrm{~d}$ ) shows that the current densities raised gradually and the anodic and cathodic peaks separation was smaller when the pyrolysis time at $1000^{\circ} \mathrm{C}$ increased from 30 minutes to $10 \mathrm{~h}$. In fact, sufficiently long carbonization time is required at $1000^{\circ} \mathrm{C}$ in order to achieve full conversion of ZIF-8 to porous carbon, with complete $\mathrm{Zn}$ removal and NPC crystallization ${ }^{40-41}$. On the other hand, further prolongation of the thermal treatment tend to decline the NPC/CF performance (Figure 4d) by decreasing the current density on the redox probe $\left[\mathrm{Fe}(\mathrm{CN})_{6}\right]^{3-} /\left[\mathrm{Fe}(\mathrm{CN})_{6}\right]^{4-}$ nearly twice for the $24 \mathrm{~h}$ pyrolysed sample. This could be explained by a possible collapse of the NPC porous structure. Indeed a large extent of collapse of the carbon skeleton has been reported in the literature when the temperature is increased above $900^{\circ} \mathrm{C}{ }^{42}$. In addition, long-term thermal treatment at $1000^{\circ} \mathrm{C}$ could also accelerate the decomposition of the $\mathrm{N}$-containing carbon framework, resulting in a lower $\mathrm{N}$ content and/or collapsed porous structure. As shown in Figure 4c, the polyhedral NPC particles are no more observed, although a granular carbon layer uniformly covers the CF surface (Figure 4c). 

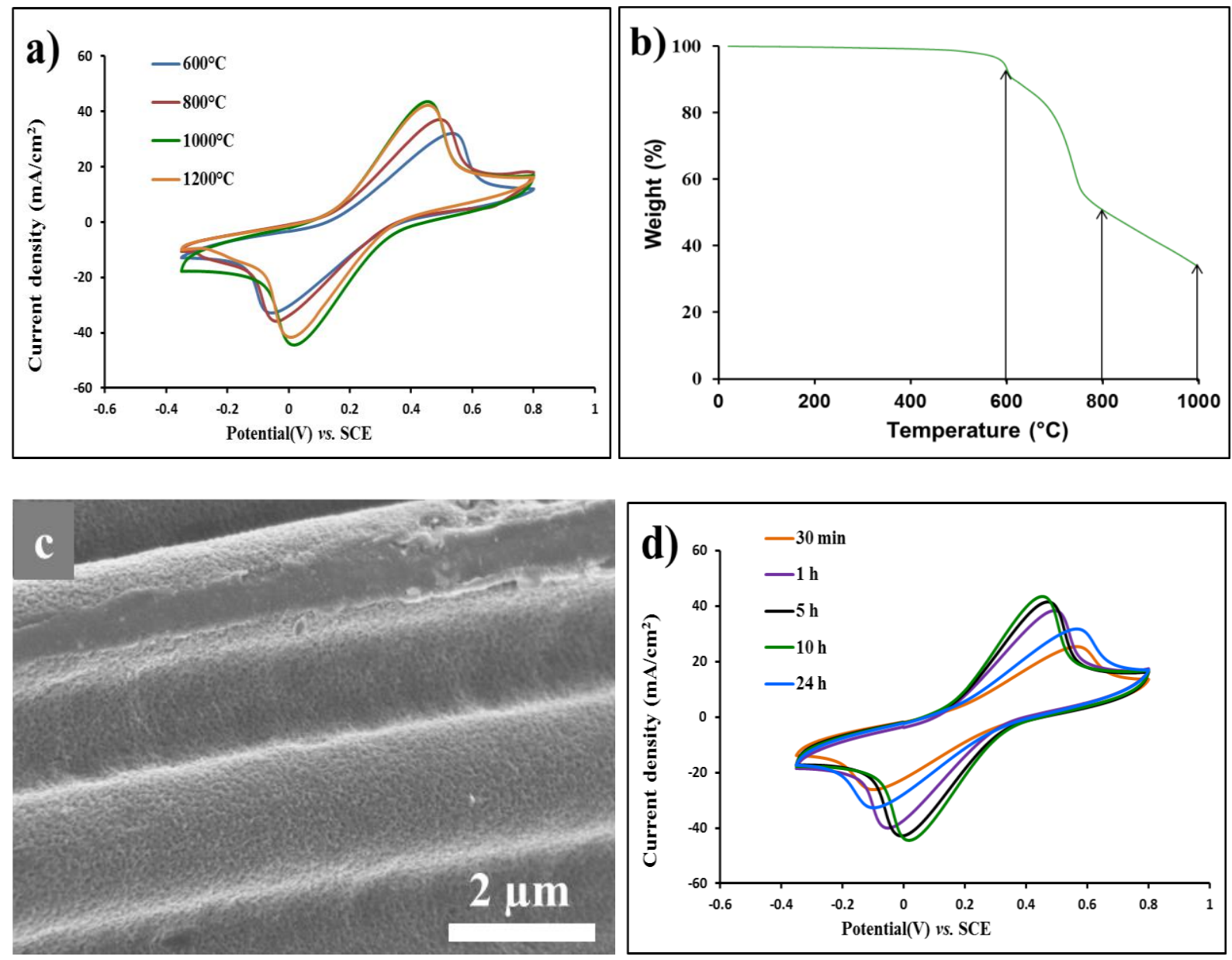

Figure 4. (a) CV curves of NPC/CFs prepared at various temperatures, (b) TGA of CF@ZIF8/ZnO composite material under $\mathrm{N}_{2}, 5^{\circ} \mathrm{C} / \mathrm{min}$, (c) SEM image of NPC/CF after $24 \mathrm{~h}$ thermal treatment, and (d) $\mathrm{CV}$ curves of NPC/CFs calcined at $1000^{\circ} \mathrm{C}$ and different heating times. $\mathrm{CV}$ conditions: potassium hexacyanoferrate solution $(10 \mathrm{mM})$ in $1 \mathrm{M} \mathrm{KNO}_{3}$. Scan rate $7 \mathrm{mV} \mathrm{s}^{-1}$.

\section{Adsorption capacity of NPC/CF}

Owing to its hierarchical porous structure, with both high surface area and open porosity, the NPC/CF material is potentially a relevant adsorbent for the elimination of water pollutants. The efficiency of NPC/CF for removing dye pollutants such as AO7 is demonstrated in Figure 5a for dye concentrations in the range $0.02 \mathrm{mM}-0.5 \mathrm{mM}$. As expected, the adsorbent efficiency declined with increasing dye concentration due to saturation of adsorption sites on the NPC/CF surface $^{43-44}$. At low concentration $(0.02 \mathrm{mM})$, over $97 \%$ of AO7 was removed after 30 min while only $8 \%$ abatement was achieved for the most concentrated solution $(0.5 \mathrm{mM})$. This 
observation is in line with the results published by Lim et al. for zeolite-activated carbon macrocomposites and showing a 6-folds adsorption decrease when the initial AO7 dye concentration increased from 100 to $400 \mathrm{mg} / \mathrm{L}^{45}$. As shown in Figure 5a, dye adsorption is very fast at the beginning of the process, and reached equilibrium after $60 \mathrm{~min}$ for all concentrations.

To shed further light on the dye adsorption mechanism, experimental data were analyzed with the help of well-known Langmuir and Freundlich models. The Langmuir adsorption isotherm predicts a monolayer adsorption on specific sites. The Langmuir equation is expressed as follows (Eq. 5)

$$
\frac{C_{e}}{Q_{e}}=\frac{1}{Q_{m} K}+\frac{C_{e}}{Q_{m}}
$$

where $Q_{e}$ is the amount adsorbed $\left(\mu \mathrm{g} . \mathrm{cm}^{-2}\right) ; C_{e}$ is the equilibrium dye concentration $\left(\mu \mathrm{g} . \mathrm{L}^{-1}\right) ; \mathrm{Q}_{\mathrm{m}}$ and $\mathrm{K}$ are Langmuir constants related to the maximum adsorption capacity and the free energy of adsorption, respectively.

The Freundlich isotherm is an empirical equation employed to describe heterogeneous systems. The logarithmic form of Freundlich model is given by Equation 6:

$$
\log Q_{e}=\log K_{f}+(1 / n) \log C_{e}
$$

where $\mathrm{K}_{\mathrm{f}}$ and $\mathrm{n}$ are Freundlich adsorption isotherm constants, being indicative of the adsorption extent and the degree of non-linearity between solution concentration and adsorption, respectively.

Figures $5 \mathrm{c}$ and $5 \mathrm{~d}$ reveal that the AO7 adsorption on NPC/CF material fits Langmuir isotherm with higher correlation coefficient $\left(\mathrm{R}^{2}=0.9998\right)$ in comparison to Freundlich isotherm $\left(\mathrm{R}^{2}=0.7941\right)$. Such results correspond well to those published elsewhere on other adsorbing materials ${ }^{46-48}$ and confirm that the adsorption process fits the monolayer adsorption model.

Another important parameter influencing adsorption efficiency is the solution $\mathrm{pH}$. The results plotted in Figure $5 \mathrm{~b}$ reveals that the $\mathrm{pH}$ of a $50 \mathrm{mM} \mathrm{Na} \mathrm{SO}_{4}$ solution remains unchanged after $2 \mathrm{~h}$ immersion of the NPC/CF in a solution at $\mathrm{pH} \leq 7$. Over this value, the $\mathrm{pH}$ tends to decrease. Such results confirm that the surface of NPC/CF material is positively charged, and is thus able to attract negative molecules like AO7 dye in aqueous medium. The positive charge of 
NPC/CF surface could be linked to the presence of nitrogen species. These charge effects also contribute to fasten initial adsorption kinetics observed in Figure 5a: at high initial AO7 concentration, the material active sites quickly saturate and the dye removal efficiency decreases remarkably. The NPC/CF material proved high adsorption capacity as its performance (calculated from Langmuir isotherm) is over 18 times higher than the value reported for zeoliteactivated carbon macrocomposites ${ }^{45}$.
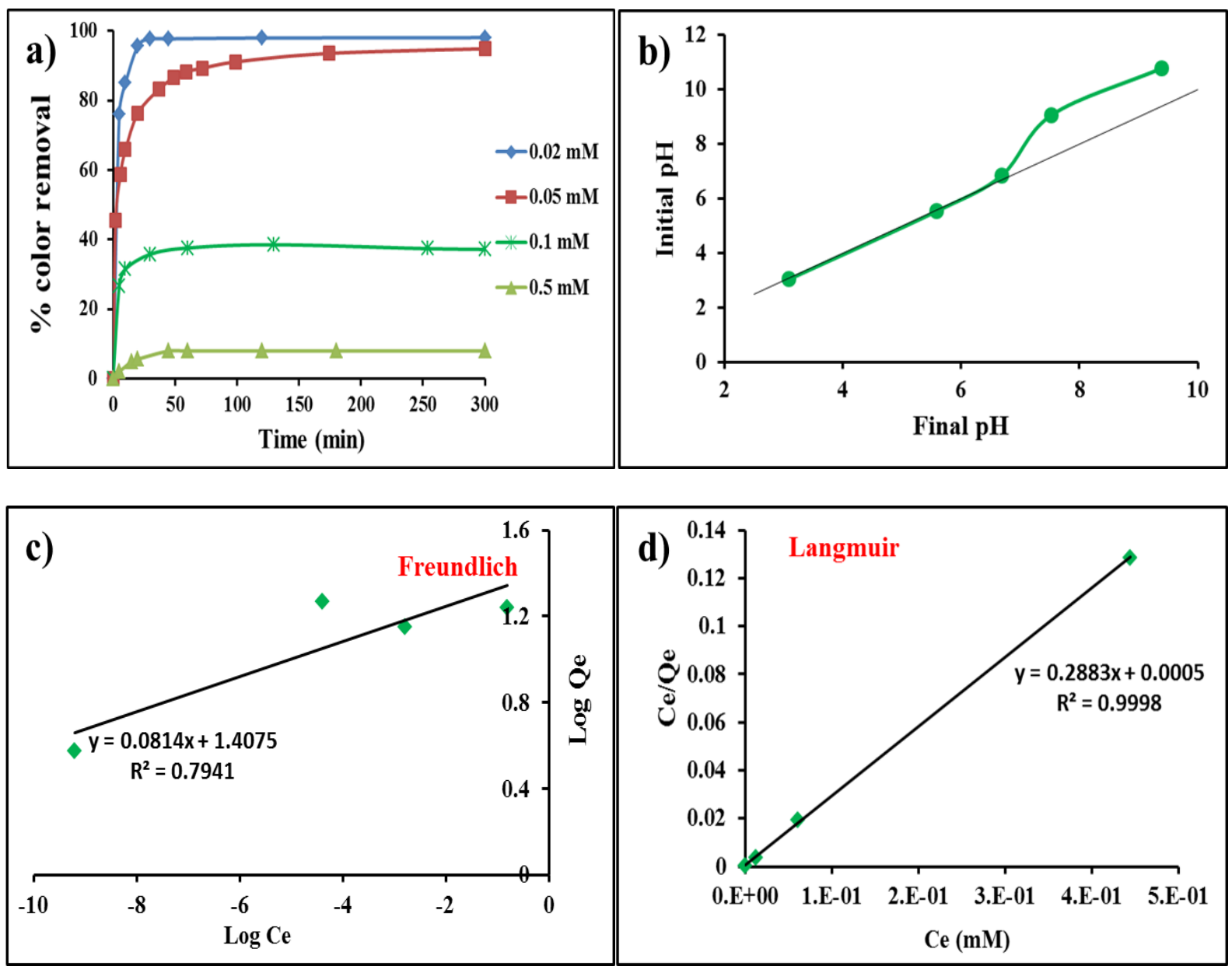

Figure 5. (a) Evolution of the \% color removal at various $\mathrm{AO} 7$ dye concentrations, (b) $\mathrm{pH}$ variation in $\mathrm{Na}_{2} \mathrm{SO}_{4}$ solution after immersing NPC/CF material for $2 \mathrm{~h}$, (c) Freundlich adsorption isotherm, and (d) Langmuir adsorption isotherm.

On the other hand, the AO7 dye adsorption virtually did not occur on raw commercial CF. This phenomenon could be attributed to both the hydrophobic property of raw CF (water 
contact angle $\left.\sim 89.9^{\circ}\right)$ and to its low specific surface area $\left(0.09 \mathrm{~m}^{2} \mathrm{~g}^{-1}\right)$. Contrarily, the NPC/CF containing N-based groups is covered with hydrophilic spots that help to drag AO7 molecules into the macroporous network of the carbon felt. At the same time, its high specific surface area ensures an effective adsorption of dye molecules. The full saturation is reached once all active sites in NPC/CF are filled with dye molecules. It can be concluded that due to its high surface area, high accessible porosity, and positively charged surface nitrogen groups, the NPC/CF material has a high adsorption capacity for the abatement of negatively-charged water pollutants. In general, the main bottleneck limiting long-term application of adsorption-based processes bears on problematic sorbent regeneration for avoiding full saturation. In order to address this issue, a coupling of adsorption with electro-Fenton process technology has been considered in the next section.

\section{System coupling electron-Fenton and adsorption processes}

As described in the experiment part, the EF experiments were carried out after immerging the NPC/CF cathode in a $0.1 \mathrm{mM}$ AO7 solution. As evidenced in Figure 6a, the removal of AO7 by the effect of adsorption reached more than $35 \%$ within $30 \mathrm{~min}$. When the adsorption equilibrium was attained (after 2 hours), iron catalyst was added to the system in order to run the EF process. As shown in Figure 6, the AO7 dye has been eliminated within 7 and 60 minutes when using either NPC/CF or raw CF, respectively. The apparent rate constant $\left(\mathrm{k}_{\mathrm{app}}\right)^{4,6,49}$, reaching values $\sim 0.8 \mathrm{~min}^{-1}$ for NPC/CF, was more than 7 times higher in comparison with the value for raw CF. In addition, from Figure $6 \mathrm{~b}$ it is clear, that TOC removal was $\sim 90 \%$ after $8 \mathrm{~h}$ with NPC/CF, while it did not overpass $60 \%$ for raw CF. Such outstanding performance could be ascribed to both high electroactive surface area and enhanced conductivity of NPC/CF material. Indeed, the higher conductivity of NPC/CF (Figure S1) promotes faster electron transport, leading to the production of higher amount of $\mathrm{H}_{2} \mathrm{O}_{2}$ by oxygen reduction reaction (ORR) ${ }^{50}$, and thus higher amounts of hydroxyl radicals $\left({ }^{\circ} \mathrm{OH}\right)$ as highly oxidizing agent. In contrast, in the case 
of raw $\mathrm{CF}$, the $\mathrm{EF}$ reaction is less pronounced because of both lower conductivity and poor hydrophilicity of the electrode. The raw CF exhibits poor electrochemical properties because of higher interfacial charge-transfer resistance $\left(\mathrm{R}_{\mathrm{ct}}\right)$ which was evidenced by the measurements of electrochemical impedance spectroscopy (Figure S1). $R_{\text {ct }}$ (inversely proportional to the exchange current density, $\mathrm{j}_{0}$ ) is related to the number of electrons that are transferred from the catalytic surface to the reactant(s). The bigger is $R_{c t}$, the lower is the kinetic rate. Thus, $R_{c t}$ should be as small as possible to enable a fast electrochemical kinetics. The decrease of $R_{c t}$ from $2.4 \Omega$ to 0.7 $\Omega$ for raw CF and NPC/CF respectively can then be explained by an increase of the active sites density caused by enhanced real electroactive surface area induced by the presence of the microporous carbon layer on the surface of CF. The excellent properties of NPC/CF for $\mathrm{H}_{2} \mathrm{O}_{2}$ production could be also explained by delocalized conjugated system with the $\mathrm{sp}^{2}$-hybridized nitrogen-doped carbon framework with lone electron pairs resulting in improved ORR performance ${ }^{17,39,51}$. This finding, revealing improved EF process efficiency in terms of lower energy consumption $\left(E_{c}\right)$, has also strong impact on the cost of $E F$ treatment. The $E_{c}$ value for $\mathrm{NPC} / \mathrm{CF}$ was around $0.54 \mathrm{kWh} \mathrm{g}^{-1} \mathrm{TOC}$ instead of $1.08 \mathrm{kWh} \mathrm{g}^{-1} \mathrm{TOC}$ for raw $\mathrm{CF}$, leading thus to $50 \%$ reduction of the total energy consumption. As summarized on Table 1, the reduction of $\mathrm{E}_{\mathrm{c}}$ value was also 1.7 times and 1.4 times higher for NPC/CF in comparison with electrodes based on graphene/carbon felt and graphene/carbon cloth, respectively. Concerning the synthesizing method, the fabrication process is simple including two uncomplicated steps: (1) Atomic Layer Deposition of zinc oxide $(\mathrm{ZnO})$ followed by its subsequent solvothermal conversion to Zeolitic Imidazolate Framework (ZIF-8) and (2) the carbonization of the asprepared material. Such synthesis protocol is very robust and does not require any strict synthesis conditions or a high quantity of expensive chemicals. The proposed method enables designing of a new material (electrode) with an outstanding electrochemical performance and long-term stability. It is applicable for biorefractory pollutants removal featuring both adsorption and electrochemical activity in electro-Fenton process. In comparison with conventional porous 
carbon (PC) of graphene layer deposited onto the commercial carbon felt (CF), the synthesis/application of the novel NPC/CF electrode proposed in this work presents several advantages: (i) The synthesis method of NPC/CF electrode does require any strict control of gas flow during thermal treatment. In contrast, to form the conventional porous carbon (PC), it is necessary to apply a mixture of $\mathrm{N}_{2} / \mathrm{O}_{2}$ with well-defined composition. If the oxygen ratio exceeds an optimal value, carbon felt $(\mathrm{CF})$ would be damaged (destroyed). Moreover, the method applied for the formation of conventional porous carbon (PC), does not allow an insertion of functional nitrogen groups which are important catalytic sites for oxygen reduction reaction (ORR) during electro-Fenton process. (ii) Better stability of NPC/CF electrode in comparison with graphene-modified CFs which sufferer from leaching of graphene into the solution during electrochemical process. It has been evidenced in previous studies that the TOC removal after $5 \mathrm{EF}$ cycles decreased by $5.4 \%$ for graphene-CF ${ }^{9}$, and $21 \%$ for Graphene/Carbon $\operatorname{cloth}^{52}$

Last but not least, the NPC/CF cathode proved significant stability after multiple reaction cycles. The TOC removal decreased by $5.4 \%$ only after 10 subsequent reaction cycles (Figure 6b). A slight decline of electrochemical performance was also observed when running the CV measurements in potassium hexacyanoferrate (Figure S2). This phenomenon was probably caused by a partial detachment of the NPC layer during the washing process conducted with deionized water. However, such decline of the TOC removal after long term operation and multiple cycling tests can be considered as negligible, in comparison with the high efficiency of the EF oxidation process.

Table 1. Mineralization efficiency of EF process applying diverse cathode materials.

\begin{tabular}{|c|c|c|c|c|c|}
\hline Cathode material & Pollutant & $\begin{array}{c}\% \text { TOC removal } \\
\text { increase* }\end{array}$ & $\begin{array}{c}\% \text { TOC } \\
\text { removal } \\
\text { decrease }^{\dagger}\end{array}$ & $\% \mathrm{E}_{\mathrm{c}}$ decrease & Ref \\
\hline $\begin{array}{c}\text { Graphene/Carbon } \\
\text { felt }\end{array}$ & $\mathrm{AO} 7$ & 33 & 6 & 29 & 9 \\
\hline Chemically & p-nitrophenol & 29 & 5 & $\mathrm{n} / \mathrm{a}$ & 17 \\
\hline
\end{tabular}




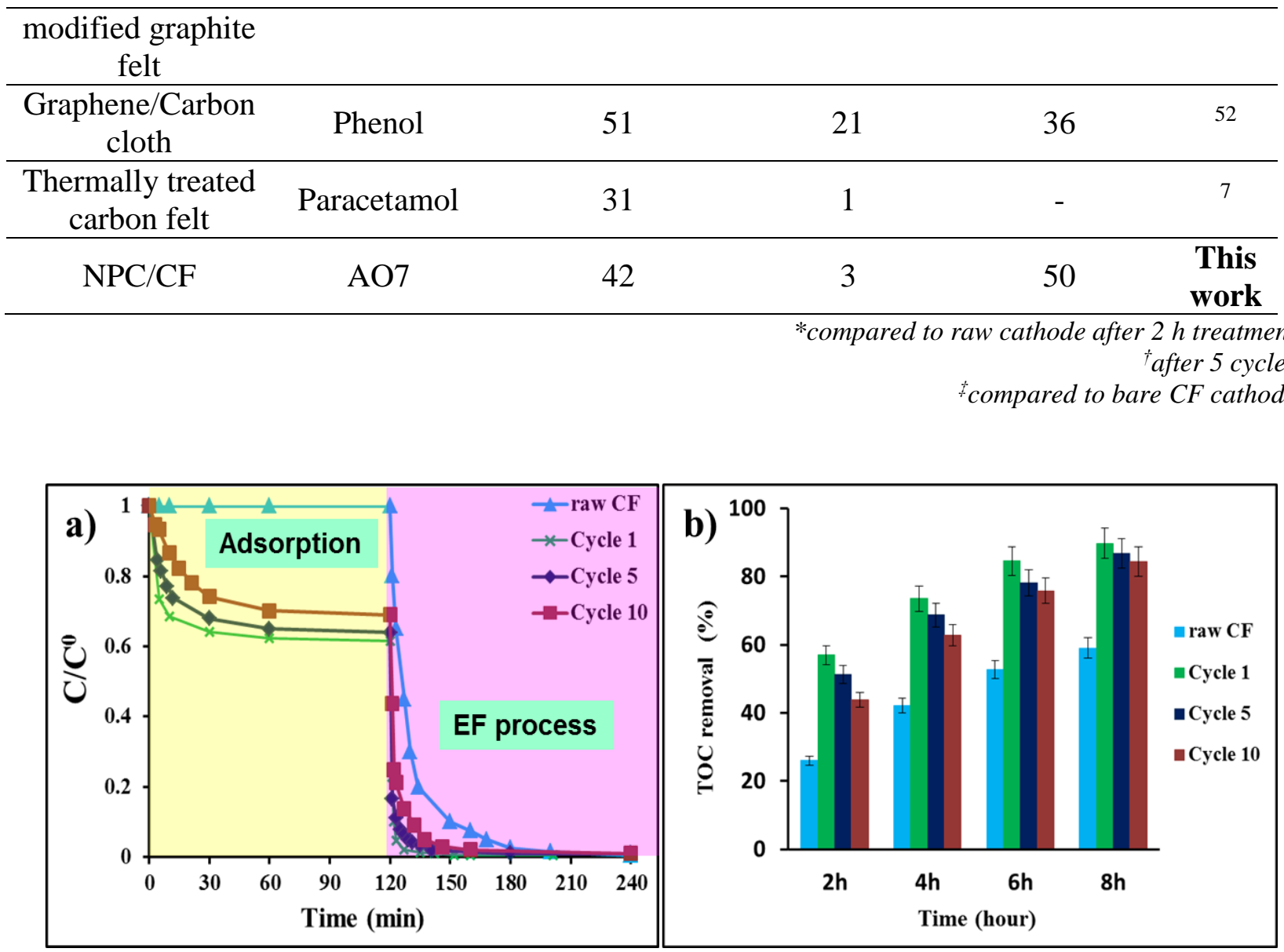

Figure 6. (a) Kinetics of AO7 removal by both adsorption and electro-Fenton processes.

(b) TOC removal after 8h; Conditions: V=50 mL, [AO7]=0.1 mM; $\left[\mathrm{Fe}^{2+}\right]=0.2 \mathrm{mM} ; \mathrm{pH}=3$;

$\left[\mathrm{Na}_{2} \mathrm{SO}_{4}\right]=50 \mathrm{mM}, \mathrm{I}=25 \mathrm{~mA}$; anode: Pt, cathode: raw $\mathrm{CF}$ and NPC/CF.

\section{CONCLUSION}

In this study, commercial carbon felts were modified by nitrogen-doped porous carbon, aiming to develop versatile carbon-based electrodes for efficient abatement of water pollutants by coupling adsorption and electron-Fenton processes. The modification has been realized by applying a synthesis strategy based on $i$ ) atomic layer deposition (ALD) of $\mathrm{ZnO}$ and ii) solvothermal conversion of $\mathrm{ZnO}$ into corresponding $\mathrm{ZIF}-8$ followed by its carbonisation treatment forming the NCP/CF electrode. Key parameters influencing the growth of nitrogendoped porous carbon layers were investigated, including $\mathrm{ZnO}$ thickness, temperature and duration of thermal treatment (carbonisation step). It has been demonstrated that the proposed 
surface modification increases hydrophilicity, conductivity and electrocatalytic activity of commercial carbon felts. The derived NPC/CF electrode was used for coupling adsorption and electro-Fenton processes in order to eliminate a model pollutant (AO7) from aqueous medium. The percentage of adsorption reached over $97 \%$ of initial $0.02 \mathrm{mM}$ dye concentration after 30 min. During the EF process, 90\% TOC removal has been achieved within $8 \mathrm{~h}$ and the apparent rate constant $\left(\mathrm{k}_{\mathrm{app}} \sim 0.8 \mathrm{~min}^{-1}\right)$ was more than 7 times higher compared to pristine $\mathrm{CF}$ commercial electrode. Moreover, the NPC/CF cathode proved lower energy consumption $(0.54$ $\mathrm{kWh} \mathrm{g}^{-1} \mathrm{TOC}$ ) compared to raw CF. At the same time, the NPC/CF electrode exhibited high reaction efficiency and system durability due to continuous regeneration of the NPC/CF sorption capacity by total mineralization of pollutants accumulated on its surface. Thanks to the versatility of the proposed protocol, enabling the synthesis of various MOFs and their subsequent carbonisation into specific porous carbons, many different electrode architectures can be possibly designed for applications in both environmental and energy-related areas. Different studies are currently under progress in these areas and will be reported in next communications.

\section{SUPPORTING INFORMATION}

Figure S1. Electrochemical impedance spectroscopy (EIS) of raw CF and NPC/CF electrodes. Figure S2. CVs of NPC/CF after 5 and 10 running cycles. Table S1. Surface area of raw CF and NPC/CF materials obtained from samples with different initial $\mathrm{ZnO}$ thickness.

\section{ACKNOWLEDGMENTS}

Authors gratefully acknowledge financial support from the Vietnamese government (VIED - Vietnam International Education Development - Project 911), the ANR project ECOTS/CElectrON and the Institut Européen des Membranes (exploratory project COMET-MOF"Next Generation Membranes"- Internal IEM Call 2015) for co-funding this research work. 


\section{REFERENCES}

1. Rodrigo, M. A.; Oturan, N.; Oturan, M. A. Electrochemically Assisted Remediation of Pesticides in Soils and Water: A Review. Chem Rev 2014, 114, 8720-45.

2. J. González-García; P. Bonete; E. Expósito; V. Montiel; A. Aldaz; Torregrosa-Maciá, R. Characterization of a Carbon Felt Electrode: Structural and Physical Properties. Journal of Materials Chemistry 1999, 9, 419-426.

3. E. Brillas; I. Sirés; Oturan, M. A. Electro-Fenton Process and Related Electrochemical Technologies Based on Fenton's Reaction Chemistry. Chem Rev 2009, 109 6570-6631.

4. Ozcan, A.; Oturan, M. A.; Oturan, N.; Sahin, Y. Removal of Acid Orange 7 from Water by Electrochemically Generated Fenton's Reagent. J Hazard Mater 2009, 163, 1213-20.

5. Panizza, M.; Oturan, M. A. Degradation of Alizarin Red by Electro-Fenton Process Using a Graphite-Felt Cathode. Electrochimica Acta 2011, 56, 7084-7087.

6. Diagne, M.; Oturan, N.; Oturan, M. A. Removal of Methyl Parathion from Water by Electrochemically Generated Fenton's Reagent. Chemosphere 2007, 66, 841-8.

7. Le, T. X. H.; Charmette, C.; Bechelany, M.; Cretin, M. Facile Preparation of Porous Carbon Cathode to Eliminate Paracetamol in Aqueous Medium Using Electro-Fenton System. Electrochimica Acta 2016, 188, 378-384.

8. Thi Xuan Huong Le; Mikhael Bechelany; Joffrey Champavert; Cretin, M. A Highly Active Based Graphene Cathode for the Electro-Fenton Reaction. RSC Adv. 2015, 5, 42536.

9. Le, T. X. H.; Bechelany, M.; Lacour, S.; Oturan, N.; Oturan, M. A.; Cretin, M. High Removal Efficiency of Dye Pollutants by Electron-Fenton Process Using a Graphene Based Cathode. Carbon 2015, 94, 1003-1011.

10. Duan, X.; Liu, W.; Chang, L. Porous Carbon Prepared by Using Zif-8 as Precursor for Capacitive Deionization. Journal of the Taiwan Institute of Chemical Engineers 2016, 62, 132139.

11. Ma, X.; Li, L.; Wang, S.; Lu, M.; Li, H.; Ma, W.; Keener, T. C. Ammonia-Treated Porous Carbon Derived from Zif-8 for Enhanced Co2 Adsorption. Applied Surface Science 2016, 369, 390-397.

12. I.A. Khan; A. Badshah; N. Haider; S. Ullah; D.H. Anjum; Nadeem, M. A. Porous Carbon as Electrode Material in Direct Ethanol Fuel Cells (Defcs) Synthesized by the Direct Carbonization of Mof-5. Journal of Solid State Electrochemistry 2014, 18, 1545-55.

13. Jiang, M.; Cao, X.; Zhu, D.; Duan, Y.; Zhang, J. Hierarchically Porous N-Doped Carbon Derived from Zif-8 Nanocomposites for Electrochemical Applications. Electrochimica Acta 2016, 196, 699-707.

14. Hu, J.; Wang, H.; Gao, Q.; Guo, H. Porous Carbons Prepared by Using Metal-Organic Framework as the Precursor for Supercapacitors. Carbon 2010, 48, 3599-3606.

15. Fu, S.; Zhu, C.; Zhou, Y.; Yang, G.; Jeon, J.-W.; Lemmon, J.; Du, D.; Nune, S. K.; Lin, Y. Metal-Organic Framework Derived Hierarchically Porous Nitrogen-Doped Carbon Nanostructures as Novel Electrocatalyst for Oxygen Reduction Reaction. Electrochimica Acta 2015, 178, 287-293.

16. Raoof, J.-B.; Hosseini, S. R.; Ojani, R.; Mandegarzad, S. Mof-Derived Cu/Nanoporous Carbon Composite and Its Application for Electro-Catalysis of Hydrogen Evolution Reaction. Energy 2015, 90, 1075-1081.

17. Zhang, L.; Su, Z.; Jiang, F.; Yang, L.; Qian, J.; Zhou, Y.; Li, W.; Hong, M. Highly Graphitized Nitrogen-Doped Porous Carbon Nanopolyhedra Derived from Zif-8 Nanocrystals as Efficient Electrocatalysts for Oxygen Reduction Reactions. Nanoscale 2014, 6, 6590-602.

18. Yuan, W.; Li, J.; Xie, A.; Chen, P.; Li, S.; Shen, Y. Practical, Cost-Effective and LargeScale Production of Nitrogen-Doped Porous Carbon Particles and Their Use as Metal-Free Electrocatalysts for Oxygen Reduction. Electrochimica Acta 2015, 165, 29-35.

19. Yuanfu Deng; Ye Xie; Kaixiang Zou; Ji, X. Review on Recent Advances in NitrogenDoped Carbons: Preparations and Applications in 
Supercapacitors. J. Mater. Chem. A 2016, 4, 1144.

20. H. Zhong; C. Deng; Y. Qiu; L. Yao; Zhang, H. Nitrogen-Doped Hierarchically Porous Carbon as Efficient Oxygen Reduction Electrocatalysts in Acid Electrolyte. J. Mater. Chem. A 2014, 2, 17047-17057.

21. Luo, Z.; Lim, S.; Tian, Z.; Shang, J.; Lai, L.; MacDonald, B.; Fu, C.; Shen, Z.; Yu, T.; Lin, J. Pyridinic N Doped Graphene: Synthesis, Electronic Structure, and Electrocatalytic Property. Journal of Materials Chemistry 2011, 21, 8038.

22. Takashi Ikeda; Mauro Boero; Sheng-Feng Huang; Kiyoyuki Terakura; Masaharu Oshima; Ozaki, J. Carbon Alloy Catalysts: Active Sites for Oxygen Reduction Reaction. J. Phys. Chem. C 2008, 112, 14706-14709.

23. Jiao, C.; Li, M.; Ma, R.; Wang, C.; Wu, Q.; Wang, Z. Preparation of a Co-Doped Hierarchically Porous Carbon from Co/Zn-Zif: An Efficient Adsorbent for the Extraction of Trizine Herbicides from Environment Water and White Gourd Samples. Talanta 2016, 152, 3218.

24. Bakhtiari, N.; Azizian, S.; Alshehri, S. M.; Torad, N. L.; Malgras, V.; Yamauchi, Y. Study on Adsorption of Copper Ion from Aqueous Solution by Mof-Derived Nanoporous Carbon. Microporous and Mesoporous Materials 2015, 217, 173-177.

25. Yan, X.; Li, X.; Yan, Z.; Komarneni, S. Porous Carbons Prepared by Direct Carbonization of Mofs for Supercapacitors. Applied Surface Science 2014, 308, 306-310.

26. Yu, M.; Zhang, L.; He, X.; Yu, H.; Han, J.; Wu, M. 3d Interconnected Porous Carbons from Mof-5 for Supercapacitors. Materials Letters 2016, 172, 81-84.

27. Liu, B.; Shioyama, H.; Jiang, H.; Zhang, X.; Xu, Q. Metal-Organic Framework (Mof) as a Template for Syntheses of Nanoporous Carbons as Electrode Materials for Supercapacitor. Carbon 2010, 48, 456-463.

28. Yi, H.; Wang, H.; Jing, Y.; Peng, T.; Wang, X. Asymmetric Supercapacitors Based on Carbon Nanotubes@Nio Ultrathin Nanosheets Core-Shell Composites and Mof-Derived Porous Carbon Polyhedrons with Super-Long Cycle Life. Journal of Power Sources 2015, 285, 281290.

29. Zou, G.; Jia, X.; Huang, Z.; Li, S.; Liao, H.; Hou, H.; Huang, L.; Ji, X. Cube-Shaped Porous Carbon Derived from Mof-5 as Advanced Material for Sodium-Ion Batteries. Electrochimica Acta 2016, 196, 413-421.

30. Lv, Z.; Chen, Y.; Wei, H.; Li, F.; Hu, Y.; Wei, C.; Feng, C. One-Step Electrosynthesis of Polypyrrole/Graphene Oxide Composites for Microbial Fuel Cell Application. Electrochimica Acta 2013, 111, 366-373.

31. Thi Xuan Huong Le; Roseline Esmilaire; Martin Drobek; Mikhael Bechelany; Cyril Vallicari; Duy Linh Nguyen; Anne Julbe; Sophie Tingry; Cretin, M. Design of a Novel Fuel Cell-Fenton System: A Smart Approach to Zero Energy Depollution. J. Mater. Chem. A 2016, 4 , 17686.

32. Viter, R.; Iatsunskyi, I.; Fedorenko, V.; Tumenas, S.; Balevicius, Z.; Ramanavicius, A.; Balme, S.; Kempiński, M.; Nowaczyk, G.; Jurga, S.; Bechelany, M. Enhancement of Electronic and Optical Properties of Zno/A12o3nanolaminate Coated Electrospun Nanofibers. The Journal of Physical Chemistry C 2016, 120, 5124-5132.

33. Shirley, D. A. High-Resolution X-Ray Photoemission Spectrum of the Valence Bands of Gold. Phys. Rev. B 1972, 5, 4709.

34. Scofield, J. H. Hartree-Slater Subshell Photoionization Cross-Sections at 1254 and 1487 Ev. Journal of Electron Spectroscopy and Related Phenomena 1976, 8, 129-137.

35. Jung, K. W.; Park, D. S.; Hwang, M. J.; Ahn, K. H. Decolorization of Acid Orange 7 by an Electric Field-Assisted Modified Orifice Plate Hydrodynamic Cavitation System: Optimization of Operational Parameters. Ultrason Sonochem 2015, 26, 22-9.

36. Ruiz, E. J.; Hernández-Ramírez, A.; Peralta-Hernández, J. M.; Arias, C.; Brillas, E. Application of Solar Photoelectro-Fenton Technology to Azo Dyes Mineralization: Effect of 
Current Density, Fe2+ and Dye Concentrations. Chemical Engineering Journal 2011, 171, 385392.

37. Drobek, M.; Bechelany, M.; Vallicari, C.; Abou Chaaya, A.; Charmette, C.; SalvadorLevehang, C.; Miele, P.; Julbe, A. An Innovative Approach for the Preparation of Confined Zif-8 Membranes by Conversion of Zno Ald Layers. Journal of Membrane Science 2015, 475, 39-46.

38. Bechelany, M.; Drobek, M.; Vallicari, C.; Abou Chaaya, A.; Julbe, A.; Miele, P. Highly Crystalline Mof-Based Materials Grown on Electrospun Nanofibers. Nanoscale 2015, 7, 5794802.

39. Alexeyeva, N.; Shulga, E.; Kisand, V.; Kink, I.; Tammeveski, K. Electroreduction of Oxygen on Nitrogen-Doped Carbon Nanotube Modified Glassy Carbon Electrodes in Acid and Alkaline Solutions. Journal of Electroanalytical Chemistry 2010, 648, 169-175.

40. Yu-Xiao Zhou; Yu-Zhen Chen; Lina Cao; Junling Lu; Jiang, H.-L. Conversion of a Metal-Organic Framework to N-Doped Porous Carbon Incorporating Co and Coo Nanoparticles. Direct Oxidation of Alcohols to Esters. Chem. Commun 2015, 51, 8292.

41. Tang, J.; Salunkhe, R. R.; Liu, J.; Torad, N. L.; Imura, M.; Furukawa, S.; Yamauchi, Y. Thermal Conversion of Core-Shell Metal-Organic Frameworks: A New Method for Selectively Functionalized Nanoporous Hybrid Carbon. J Am Chem Soc 2015, 137, 1572-80.

42. Chao, S.; Zou, F.; Wan, F.; Dong, X.; Wang, Y.; Guan, Q.; Wang, G.; Li, W. NitrogenDoped Carbon Derived from Zif-8 as a High-Performance Metal-Free Catalyst for Acetylene Hydrochlorination. Sci Rep 2017, 7, 39789.

43. Eren, Z.; Acar, F. N. Adsorption of Reactive Black 5 from an Aqueous Solution: Equilibrium and Kinetic Studies. Desalination 2006, 194, 1-10.

44. Nagarethinam Kannan; Sundaram, M. M. Kinetics and Mechanism of Removal of Methylene Blue by Adsorption on Various Carbons-a Comparative Study. Dyes and Pigments 2001, 51, 25-40.

45. Lim, C. K.; Bay, H. H.; Neoh, C. H.; Aris, A.; Abdul Majid, Z.; Ibrahim, Z. Application of Zeolite-Activated Carbon Macrocomposite for the Adsorption of Acid Orange 7: Isotherm, Kinetic and Thermodynamic Studies. Environ Sci Pollut Res Int 2013, 20, 7243-55.

46. Moussavi, G.; Mahmoudi, M. Removal of Azo and Anthraquinone Reactive Dyes from Industrial Wastewaters Using Mgo Nanoparticles. J Hazard Mater 2009, 168, 806-12.

47. Lin, J.; Zhan, Y. Adsorption of Humic Acid from Aqueous Solution onto Unmodified and Surfactant-Modified Chitosan/Zeolite Composites. Chemical Engineering Journal 2012, 200-202, 202-213.

48. Sathishkumar, P.; Arulkumar, M.; Palvannan, T. Utilization of Agro-Industrial Waste Jatropha Curcas Pods as an Activated Carbon for the Adsorption of Reactive Dye Remazol Brilliant Blue R (Rbbr). Journal of Cleaner Production 2012, 22, 67-75.

49. Hammami, S.; Bellakhal, N.; Oturan, N.; Oturan, M. A.; Dachraoui, M. Degradation of Acid Orange 7 by Electrochemically Generated (*)Oh Radicals in Acidic Aqueous Medium Using a Boron-Doped Diamond or Platinum Anode: A Mechanistic Study. Chemosphere 2008, 73, 678-84.

50. Pajootan, E.; Arami, M.; Rahimdokht, M. Discoloration of Wastewater in a Continuous Electro-Fenton Process Using Modified Graphite Electrode with Multi-Walled Carbon Nanotubes/Surfactant. Separation and Purification Technology 2014, 130, 34-44.

51. Z.H. Sheng; L. Shao; J.J. Chen; W.J. Bao; F.B. Wang; X.H. Xia Synthesis of NitrogenDoped Graphene Via Thermal Treatment of Graphene Oxide within Methylimidazole and Its Capacitance Performance as Electric Double Layer Capacitor. ACS Nano 2011, 5, 4350.

52. Mousset, E.; Ko, Z. T.; Syafiq, M.; Wang, Z.; Lefebvre, O. Electrocatalytic Activity Enhancement of a Graphene Ink-Coated Carbon Cloth Cathode for Oxidative Treatment. Electrochimica Acta 2016, 222, 1628-1641. 
TOC Graphic

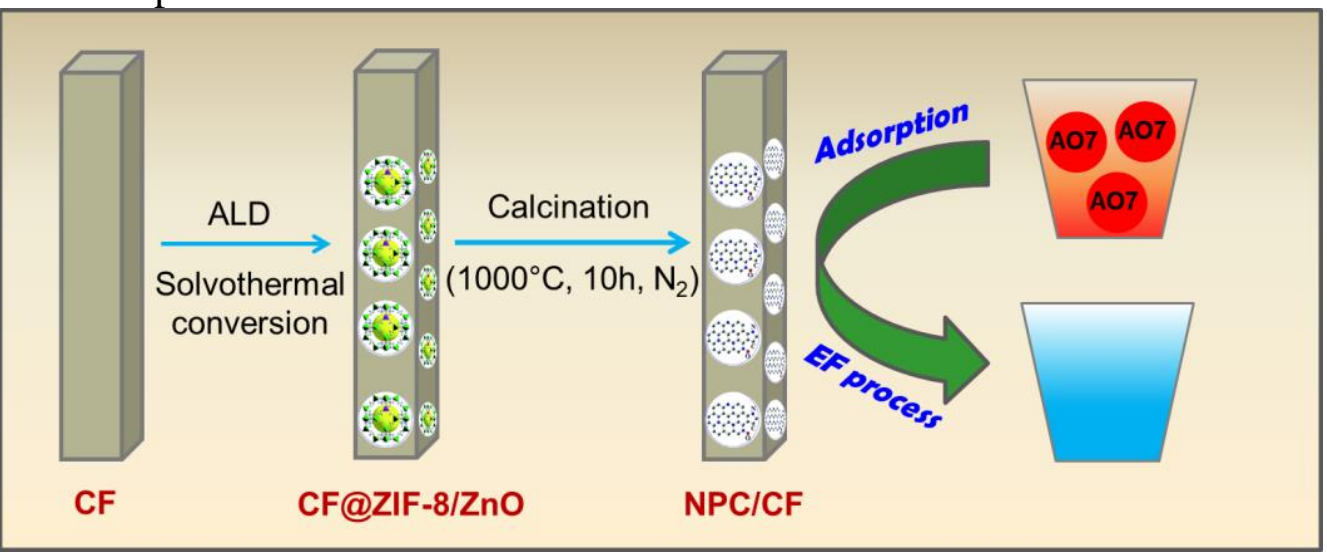

